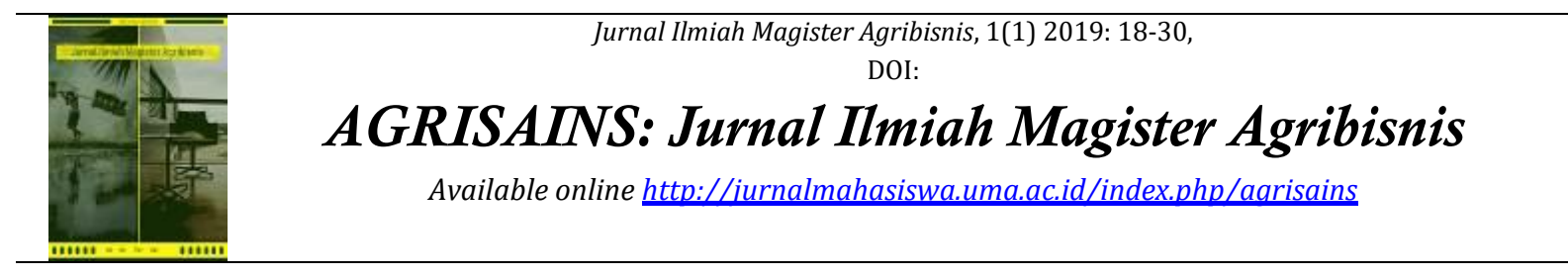

\title{
Analisis Studi Kelayakan Bisnis Pemanfaatan Limbah Agribisnis Menjadi Energi Alternatif di Kecamatan Tanah Jawa Kabupaten Simalungun
}

\section{The Analysis of Business Feasibility Study on the Utilization of Agribusiness Waste As An Alternative Energy in Tanah Jawa Sub-District Simalungun Regency}

\author{
Arief Muhazir Insandi1), Retna Astuti K.2), M. Buhari Sibuea ${ }^{3)}$
}

1) Program Studi Magister Agribisnis, Pascasarjana, Universitas Medan Area, Indonesia

2) Magister Agribisnis, Pascasarjana, Universitas Medan Area, Indonesia

2) Departemen Agribisnis, Universitas Muhammadiyah Sumatera Utara, Indonesia

\section{Abstrak}

Penelitian ini bertujuan untuk mengetahui kelayakan bisnis pemanfaatan limbah agribisnis (sekam padi dan tongkol jagung) menjadi energi alternatif di Kecamatan Tanah Jawa Kabupaten Simalungun. Penelitian ini dilakukan selama enam bulan mulai Bulan Juni sampai dengan Bulan Desember 2016. Penelitian ini menganalisis pasar dan pemasaran dari limbah sekam padi dan tongkol jagung menjadi briket arang dan menganalisis kelayakan investasi pembangunan instalasi briket arang di Kecamatan Tanah Jawa, Kabupaten Simalungun. Sampel dalam penelitian ini adalah pengusaha kilang padi dan kilang jagung yang tersebar di Kecamatan Tanah Jawa, Kabupaten Simalungun. Metode penentuan sampel yang digunakan yaitu metode sampel jenuh yaitu proses pengambilan sampel yang dilakukan dengan sengaja dimana karena jumlah populasi kecil maka semua populasi dijadikan sampel penelitian. Sampel dari kilang padi sebanyak 2 kilang sedang sampel dari kilang jagung sebanyak 4 kilang. Metode analisis data menggunakan analisis pendapatan, analisis finansial kelayakan usaha, dan analisis sensitivitas. Hasil penelitian menunjukkan bahwa pemanfaatan limbah sekam padi dan tongkol jagung menjadi energi alternatif (briket arang) di Kecamatan Tanah Jawa, Kabupaten Simalungun layak dan menguntungkan untuk diusahakan.

Kata Kunci: Briket Arang, Sekam Padi, Tongkol Jagung, Pendapatan, Kelayakan

\section{Abstract}

This study aims to determine the business feasibility of utilizing agribusiness waste (rice husks and corncobs) into alternative energy in Tanah Jawa District, Simalungun Regency. This research was conducted for six months from June to December 2016. This study analyzed the market and marketing of rice husk waste and corn cobs into charcoal briquettes and analyzed the feasibility of investment in the construction of charcoal briquette installations in Tanah Jawa District, Simalungun Regency. The samples in this study were entrepreneurs of rice refineries and corn refineries spread in Tanah Jawa District, Simalungun Regency. The sampling method used is the saturated sample method, which is a deliberate sampling process wherein because the population is small, all populations are sampled. Samples from rice refineries were 2 refineries, while samples from corn refineries were 4 refineries. Data analysis methods use income analysis, business feasibility financial analysis, and sensitivity analysis. The results showed that the utilization of rice husk waste and corncobs into alternative energy (charcoal briquettes) in Tanah Jawa District, Simalungun Regency was feasible and profitable to be cultivated.

Keywords: Charcoal Briquettes, Rice Husk, Corn Cobs, Income, Feasibility

How to Cite: Insandi, A.M., R.A. Kuswardani dan M. B. Sibuea (2017). Analisis Studi Kelayakan Bisnis Pemanfaatan Limbah Agribisnis menjadi Energi Alternatif di Kecamatan Tanah Jawa Kabupaten Simalungun. Jurnal Ilmiah Magister Agribisnis, 1(1) 2019: 18-30,

*E-mail: retnaastuti@uma.ac.id

ISSN 2550-1305 (Online)

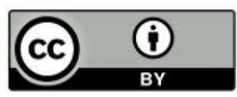


Insandi, M.A., R.A. Kuswardani dan M.B. Sibuea . Analisis Studi Kelayakan Bisnis Pemanfaatan Limbah Agribisnis Menjadi Energi Alternatif di Kecamatan Tanah Jawa Kabupaten Simalungun.

\section{PENDAHULUAN}

Briket Arang merupakan salah satu sumber energi alternatif yang dapat diperbarui di Indonesia. Potensi biomassa yang cukup besar untuk dapat dimanfaatkan adalah limbah kayu, sekam padi, jerami, ampas tebu, tempurung kelapa, cangkang sawit, kotoran ternak dan sampah kota (Putri dkk., 2017). Ketersediaan minyak tanah dianggap sebagai keperluan rumah tangga namun dengan seiring berjalannya waktu minyak tanah akan langka dan gas LPG merupakan alternatif lain, namun dianggap masih memberatkan masyarakat. Oleh karena itu dibutuhkan energi alternatif yang dapat diperbarui, murah dan mudah didapatkan sebagai bahan bakar untuk keperluan rumah tangga.

Kebutuhan energi dalam berbagai sektor di Indonesia mengalami peningkatan seiring dengan laju pertumbuhan populasi dan ekonomi nasional. Selama ini sumber energi yang digunakan di Indonesia masih banyak menggunakan sumber energi yang tidak terbarukan, seperti bahan bakar minyak. Potensi biomassa yang dihasilkan di Indonesia khususnya di Sumatera Utara sangatlah besar baik limbah cair, gas maupun padatan. Di Sumatera Utara khususnya di Kabupaten Simalungun sendiri produk pertanian seperti tanaman padi dan jagung berpotensi besar menghasilkan limbah biomassa berupa sekam padi dan tongkol jagung.

Biomassa merupakan sumber energi utama ketiga terbesar di dunia, setelah minyak dan batubara. Pemanfaatan biomassa sebagai bahan bakar alternatif pengganti bahan bakar fosil merupakan salah satu pilihan pengembangan mekanisme bersih (clean development mechanism, CDM) untuk mengurangi emisi karbon ke atmosfer. Limbah pertanian dapat menghasilkan energi kalor sekitar $6000 \mathrm{kal} / \mathrm{g}$. Limbah pertanian yang terdiri dari sekam memiliki kadar karbon 1,33\%, jerami mempunyai kadar karbon $2,71 \%$ dan tempurung kelapa memiliki kadar karbon yang tinggi sebesar $18,80 \%$ (Pancapalaga, 2008 dalam Putri dkk. 2017).

Menurut Amanda dkk. (2012) cit. Patandung (2014) briket arang merupakan bahan bakar padat yang menggunakan perekat dan tekanan, yang mengandung senyawa karbon, mempunyai nilai kalori yang relatif tinggi, dan dapat menyala dalam waktu yang cukup lama. Perkembangan energi baru dan terbarukan merupakan suatu energi alternative yang berbahan biomassa yang dapat dikembangkan lebih lanjut menjadi bahan bakar padat atau briket (Patandung, 2014). Biomassa merupakan salah satu jenis bahan bakar pada yang berasal dari sumber hayati seperti daunan, rumput, limbah pertanian dan rumah tangga. Menurut Putri dkk. (2017) Biomassa merupakan sumber energi utama ketiga terbesar di dunia, setelah minyak dan batu bara. Limbah pertanian dapat menghasilkan energi kalor sekitar $6000 \mathrm{kal} / \mathrm{g}$. Berbagai limbah pertanian dapat diolah menjadi briket arang, menurut penelitian Patandung. (2014) bahwa arang tempurung pada dapat diolah menjadi briket dengan variasi perekat tepung kanji sebanyak 2-4\% dengan nilai kalori sebesar 5.047,27 - 5.219 kal/g.

Hasil penelitian Anggoro dkk. (2014) tentang pembuatan briket arang dari campuran tempurung kelapa dan serbuk gergaji kayu sengon menyimpulkan bahwa komposisi bahan bakar yang memiliki kalor lebih tinggi maka nilai kalor campuran 
briket akan semakin tinggi. Nurhilal dkk. (2017) menyebutkan bahwa salah satu bahan baku yang memungkinkan untuk membuat briket adalah sekam padi. Sekam padi memiliki sifat-sifat dan kandungan yang baik ide dalamnya antara lain bahan baku industri kimia terutama kandungan zat kimia, bahan baku industri bahan bangunan terutama kandungan silika (SiO2) yang dapat digunakan untuk campuran pada pembuatan emen, portland, bahan isolasi dan campuran pada industri bata merah, dan sumber energi panas karena kadar selulosanya cukup tinggi sehingga dapat memberikan pembakaran yang merata dan stabil (Sinar Tani, Badan Litbang Pertanian, 2008 cit. Nurhilal dkk., 2017). Sekam padi dan tongkol jagung merupakan limbah yang dihasilkan dari tanaman palawija yang biasa digunakan sebagai campuran tanah untuk media tanam tumbuhan setelah melalui proses pengarangan. Selain itu, sekam padi dan tongkol jagung dapat dimanfaatkan sebagai bahan baku arang briket.

Briket Briket arang memiliki beberapa manfaat diantaranya untuk menghangatkan ruangan, untuk menghangatkan kandang ayam pada industri peternakan ayam, untuk memanggang dan memasak makanan, untuk mengurangi pencemaran lingkungaan dengan memanfaatkan limbah, dan untuk mengurangi pemakaian energi yang berasal dari fosil. Dari hasil evaluasi, pemanfaatan briket untuk menghangatkan ruangan di negara kita tidak memungkinkan, karena negara Indonesia merupakan negara yang beriklim tropis.

Dari uraian di atas maka peneliti ingin menghitung kelayakan energi alternatif bentuk bahan bakar yang banyak dikembangkan yang memiliki nilai tambah, terutama pada masyarakat adalah briket arang. Briket merupakan bahan bakar alternatif yang menyerupai arang dan memiliki kerapatan yang lebih tinggi. Dalam hal ini peneliti akan menghitung kelayakan briket arang dengan menggunakan bahan baku dari sekam padi dan tongkol jagung yang merupakan limbah dari kilang padi dan kilang jagung yang ada di Kecamatan Tanah Jawa, Kabupaten Simalungun.

\section{METODE PENELITIAN}

Penelitian ini dilaksanakan di Kecamatan Tanah Jawa, Kabupaten Simalungun, Sumatera Utara. Penelitian ini dilaksanakan pada bulan Juni 2016 sampai dengan bulan Desember 2016. Bentuk penelitian yang digunakan adalah studi kasus karena penelitian ini bertujuan untuk mengetahui kelayakan pendirian bisnis briket arang di Kecamatan Tanah Jawa dengan beberapa aspek kelayakan. Analisis yang digunakan dalam penelitian ini adalah analisis kuantitatif dan kualitatif. Analisis kuantitatif diperoleh dengan menggunakan kalkulasi software microsoft excel yang meliputi analisis finansial pembangunan instalasi briket yang menggunakan kriteria-kriteria kelayakan investasi Net Present Value (NPV), Internal Rate Return (IRR), Net Benefit Cost Ratio (Net B/C), Payback Period, dan Analisis Sensivitas. Analisa kualitatif digunakan untuk memperoleh gambaran aspek teknis dan aspek pemasaran. Dalam melakukan penelitian terhadap aspek pasar dan pemasaran perlu diadakan penelitian terhadap beberapa hal yang perlu diperhatikan yaitu permintaan, penawaran, proyeksi permintaan dan penawaran, proyeksi penjualan, produk (barang/jasa), segmentasi pasar, strategi dan implementasi pemasaran (ahmad, 2008). 
Insandi, M.A., R.A. Kuswardani dan M.B. Sibuea . Analisis Studi Kelayakan Bisnis Pemanfaatan Limbah Agribisnis Menjadi Energi Alternatif di Kecamatan Tanah Jawa Kabupaten Simalungun.

NPV (Net Present Value) merupakan selisih antara present value benefit dengan present value cost.

Rumus:

$$
N P V=\sum_{t=1}^{n} \frac{B t-C t}{(1+i) t}
$$

Keterangan:

$\mathrm{NPV}=$ Net Present Value

$\mathrm{B}_{\mathrm{t}} \quad=$ Present Value Benefit

$\mathrm{C}_{\mathrm{t}} \quad=$ Present Value Cost

$\mathrm{i} \quad=$ Discount Factor

$\mathrm{n} \quad=$ Tahun (Waktu)

Dari formulasi NPV di atas kelayakan proyek dapat dilaksanakan dengan ketentuan sebagai berikut:

Tabel 1. Kelayakan NPV berdasarkan Nilai NPV

\begin{tabular}{ll}
\hline Nilai NPV & Kelayakan \\
\hline $\mathrm{NPV}>0$ & Layak \\
$\mathrm{NPV}<0$ & Tidak Layak \\
$\mathrm{NPV}=0$ & Proyek dalam keadaan BEP \\
\hline
\end{tabular}

Sumber : Sinaga, (2009)

IRR (Internal Rate of Return) merupakan tingkat pengembalian internal yaitu kemampuan suatu proyek menghasilkan return (dalam satuan \%). Perhitungan IRR dengan cara interpolasi. Jika diperoleh NPV positif, maka NPV negatif dengan cara meningkatkan discount factornya.

Rumus:

$$
I R R=i_{1}+\frac{N P V_{1}}{N P V_{1}-N P V_{2}}\left(i_{2}-i_{1}\right)
$$

Indikator IRR :

- Jika IRR > DF, discount rate yang berlaku maka proyek layak dilaksanakan

- Jika IRR < DF, discount rate yang berlaku, maka proyek tidak layak

Payback Period merupakan jangka waktu periode yang diperlukan untuk membayar kembali semua biaya-biaya yang telah dikeluarkan dalam investasi suatu proyek. Indikator Payback Period yaitu semakin cepat kemampuan proyek mampu mengembalikan biaya-biaya yang telah dikeluarkan dalam investasi proyek maka proyek semakin baik (satuan waktu).

$$
\text { Rumus: } \quad \mathrm{PP}=\frac{\mathrm{I}}{\mathrm{Ab}}
$$

Keterangan :

PP $\quad=$ Payback Period

I = besarnya biaya investasi

$\mathrm{Ab} \quad=$ benefit bersih yang diperoleh setiap tahunnya 
Analisis sensitivitas merupakan analisis yang dilakukan untuk mengetahui akibat dari perubahan parameter-parameter produksi terhadap perubahan kinerja sistem produksi dalam menghasilkan keuntungan. Dengan melakukan analisis sensitivitas maka akibat yang mungkin terjadi dari perubahan-perubahan tersebut dapat diketahui dan diantisipasi sebelumnya. Setelah melakukan analisis dapat diketahui seberapa jauh dampak perubahan tersebut terhadap kelayakan proyek: pada tingkat mana proyek masih layak dilaksanakan. Analisis sensitivitas dilakukan dengan menghitung IRR, NPV, B/C ratio, dan payback period pada beberapa skenario perubahan yang mungkin terjadi (Jumingan, 2009).

\section{HASIL DAN PEMBAHASAN}

Kilang Padi PT. Lumbung Padi Jie Brothers merupakan kilang padi terbanyak mengolah dibandingkan kilang padi lainnya yaitu rata-rata sebesar $1.300 .000 \mathrm{~kg} / \mathrm{bulan}$ dengan jumlah limbah sekam padi yang dihasilkan sebanyak $390.000 \mathrm{~kg} / \mathrm{bulan}$, sedangkan untuk kilang jagung yang paling banyak mengolah perbulannya adalah Kilang Jagung Mekar Sari yaitu sebesar $65.000 \mathrm{~kg} /$ bulan dengan jumlah limbah tongkol jagung yang dihasilkan sebanyak $19.500 \mathrm{~kg} /$ bulan dapat dilihat pada tabel 2. Jumlah limbah pertanian berupa sekam padi dan tongkol jagung yang ada di Kecamatan Tanah Jawa sangat berpotensi untuk diolah menjadi briket arang yang mendatangkan keuntungan, baik secara ekonomi maupun kebersihan lingkungan.

Berdasarkan luas penggunaan lahan sawah di Kabupaten Simalungun pada tahun 2015, dapat dihitung potensi sekam padi di Kabupaten Simalungun sebesar 52.071 ton dengan asumsi hasil panen 5-6 ton/hektar.(Sumber: BPS Kab. Simalungun). Berdasarkan luas panen tanaman jagung di Kabupaten Simalungun pada tahun 2015, dapat dihitung potensi tongkol jagung di Kabupaten Simalungun dengan asumsi hasil panen sebesar 10 ton perhektar. Rata-rata potensi sekam padi dan tongkol jagung yang ada di Kecamatan Tanah Jawa, Kabupaten Simalungun Tahun 2015 dapat dilihat pada tabel berikut ini.

Tabel 2. Potensi Sekam Padi dan Tongkol Jagung

\begin{tabular}{|c|c|c|c|c|c|}
\hline NAMA KILANG & $\begin{array}{l}\text { MENGOLAH } \\
\text { (kg/bulan) }\end{array}$ & $\begin{array}{l}\text { LIMBAH } \\
\text { DIHASILKAN } \\
\text { (kg/bulan) }\end{array}$ & YANG & \multicolumn{2}{|c|}{ KETERANGAN } \\
\hline Kiang Padi Ganda & 80.000 & & 24.000 & $\begin{array}{r}\text { Randemen } 70 \% \\
\text { dengan } 80 \%\end{array}$ & sampai \\
\hline $\begin{array}{l}\text { Kilang Jagung Sinar Alam } \\
\text { Jaya }\end{array}$ & 50.000 & & 20.000 & Randemen $60 \%$ & \\
\hline Kilang Jagung Saudara Tani & 32.000 & & 12.800 & Randemen $60 \%$ & \\
\hline $\begin{array}{l}\text { Kilang Padi PT. Lumbung } \\
\text { Padi Jie Brothers }\end{array}$ & 1.300 .000 & & 390.000 & $\begin{array}{c}\text { Randemen } 70 \% \\
\text { dengan } 80 \%\end{array}$ & sampai \\
\hline Kilang Jagung Mekar Sari & 65.000 & & 19.500 & Randemen $60 \%$ & \\
\hline Kilang Jagung RG & 120.000 & & 48.000 & Randemen $60 \%$ & \\
\hline
\end{tabular}

Sumber : Data Primer (diolah), 2016

Selama ini sebagian besar pelaku usaha briket arang lebih membidik pasar ekspor untuk memasarkan produk-produknya. Strategi pemasaran ini dipilih pelaku usaha 
Insandi, M.A., R.A. Kuswardani dan M.B. Sibuea . Analisis Studi Kelayakan Bisnis Pemanfaatan Limbah Agribisnis Menjadi Energi Alternatif di Kecamatan Tanah Jawa Kabupaten Simalungun.

karena tingkat permintaan pasar luar negeri yang cenderung cukup tinggi setiap tahunnya, yaitu mencapai angka 80\%. Beberapa negara tujuan ekspor briket arang yang cukup potensial antara lain negara-negara di kawasan Timur Tengah, Jepang, Australia, Korea, dan lain sebagainya.Yang perlu diperhatikan pelaku usaha untuk memenuhi permintaan pasar ekspor adalah menjaga kualitas produk yang ditawarkan. Salah satunya seperti memastikan bahan baku briket arang, agar kualitas api yang dihasilkan bisa sempurna.

Disamping memenuhi permintaan pasar ekspor, bisnis ini juga membuka sistem keagenan untuk mengoptimalkan pemasaran lokal. Strategi ini terbilang cukup efektif untuk memperluas jangkauan pemasaran lokal dan nasional, serta memperkenalkan produk bahan bakar alternatif kepada seluruh lapisan masyarakat, baik masyarakat pedesaan yang kesulitan mendapatkan pasokan BBM maupun kalangan masyarakat menengah keatas di wilayah perkotaan.

Sampai hari ini permintaan pasar nasional masih sangat kurang, yakni sekitar 20\% untuk permintaan lokal dan sisanya (80\%) didominasi oleh permintaan pasar ekspor. Kurangnya sosialisasi dan promosi di pasar lokal, menjadikan briket arang ini kurang dikenal masyarakat luas, sehingga tidak heran bila bahan bakar briket arang lebih banyak dikonsumsi masyarakat terpencil yang daerahnya belum mendapatkan pasokan BBM maupun gas elpiji secara rutin.

\section{Analisis Ekonomi Dan Keuangan}

Untuk menganalisis ekonomi dan keuangan terlebih dahulu ditetapkan asumsi teknis dan keuangan.Hal ini dapat dilihat pada tabel 3.

Asumsi kapasitas olah pengolahan briket arang dari tabel 3 dapat dihitung sebagai berikut.

$$
\begin{array}{rlrl}
\text { Kapasitas olah } & =\text { kapasitas ruang bakar x } 60 / \text { lama pembakaran } \\
& =2.000 \mathrm{~kg} \times 60 / 200 \\
& =600 \quad \mathrm{~kg} / \mathrm{jam} \\
& =4.200 & \mathrm{~kg} / \mathrm{hari} \\
& =105.000 & \mathrm{~kg} / \mathrm{bulan}
\end{array}
$$

Sumber Rumus: Naibaho (1996) 
Tabel 3. Asumsi Teknis

\begin{tabular}{llr}
\hline Asumsi Teknis & Satuan & Jumlah \\
\hline Periode produksi & Jam & 12 \\
Hari kerja seminggu & Hari & 6 \\
Minggu per tahun & Minggu & 52 \\
Hari per tahun & Hari & 312 \\
Jumlah produksi arang briket perbulan & Kg/bulan & 105.000 \\
Jumlah produksi arang briket pertahun & Kg/tahun & 32.760 .000 \\
Tenaga kerja & & \\
Administrasi dan manajemen & Orang & 1 \\
Produksi & Orang & 20 sip) \\
Harga jual ke produsen & & 0,5 \\
Ekspor & US\$/KG & 2.000 \\
Lokal & Rp/kg & \\
Modal investasi & & 20 \\
Pajak & $\%$ & 12 \\
Bunga & $\%$ & 5 \\
Umur ekonomis peralatan & Tahun & 100 \\
Harga bahan baku & & 100 \\
Sekam padi & Rp/kg & 5.600 \\
Tongkol jagung & Rp/kg & \\
Tepung tapioca & Rp/kg & \\
\hline Sumber : Data Primer $(d i a h)$ & & \\
\hline
\end{tabular}

Sumber : Data Primer (diolah), 2016

\section{Analisis Arus Kas}

Untuk mengetahui perkembangan arus uang masuk dan arus uang keluar produksi arang briket dapat dilihat pada Tabel.5 berikut ini: 
Insandi, M.A., R.A. Kuswardani dan M.B. Sibuea . Analisis Studi Kelayakan Bisnis Pemanfaatan Limbah Agribisnis Menjadi Energi Alternatif di Kecamatan Tanah Jawa Kabupaten Simalungun.

Tabel 4. Analisis Arus Kas (Rp 000)

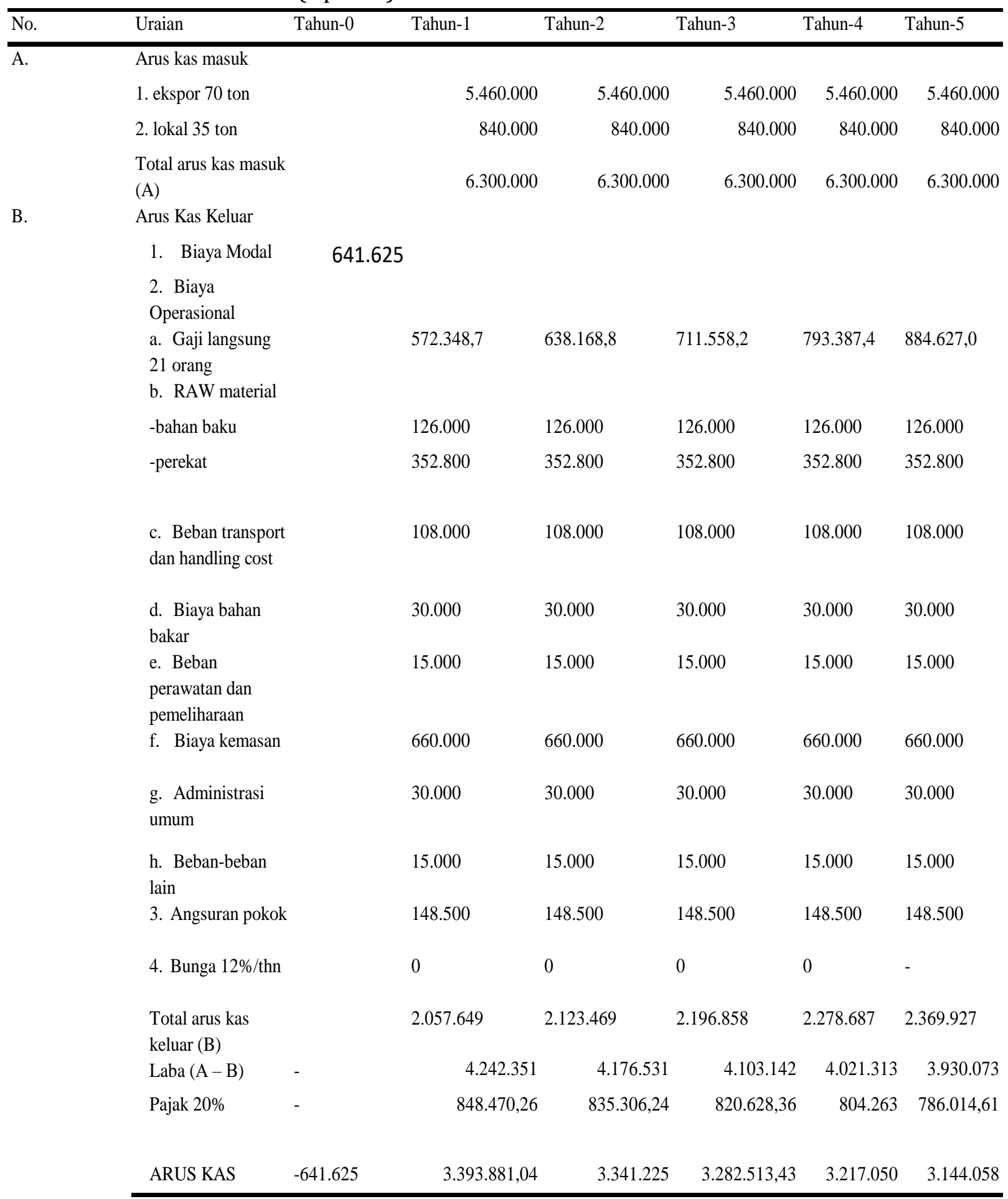

Sumber :Data Primer (diolah), 2016

Tabel 4 menjelaskan bahwa asumsi total arus kas masuk tahun ke 5 sebesar Rp. 6.300.000.000,- , sedangkan asumsi total arus kas keluar pada tahun ke 5 sebesar Rp. 2.039.883.000,- jadi diperoleh total kas pada tahun kelima sebesar Rp. 3.408.093.000,setelah dipotong pajak sebesar $20 \%$.

UMK Medan tahun 2015 sebesar Rp 2.037.000 dikalikan 11,5 \% maka kenaikan upah sebesar Rp 234.255 atau UMK Medan 2016 diperkirakan menjadi Rp 2.271.225. Seluruh 
kabupaten/kota di Sumut diminta untuk menetapkan Upah Minum Kota/Kabupaten (UMK) tahun 2016 sesuai dengan aturan PP No. 78, tentang pengupahan. Artinya kenaikan UMK juga disesuaikan dengan nilai inflasi dan pertumbuhan ekonomi. Maka peneliti mengasumsikan setiap tahunnya UMK naik sebesar $10 \%$.

Perhitungan biaya modal / investasi dapat dilihat pada tabel berikut ini.

Tabel 5. Perhitungan Biaya Modal

\begin{tabular}{|c|c|c|c|c|}
\hline \multirow{2}{*}{ URAIAN } & \multirow[t]{2}{*}{ VOL. } & \multirow[t]{2}{*}{ SATUAN } & \multicolumn{2}{|c|}{ HARGA SATUAN JUMLAH HARGA } \\
\hline & & & $(\mathbf{R p})$ & $(\mathbf{R p})$ \\
\hline 1 Harga Pengadaan Lahan (Lokasi pinggir kota) & 400,00 & $\mathrm{~m} 2$ & 200.000 & 80.000 .000 \\
\hline 2 Pengadaan Mobil Pick-up (bekas) & 1,00 & Unit & 100.000 .000 & 100.000 .000 \\
\hline 3 Pembangunan kantor (Adm, Pemasaran) \& Toilet/KM+ Perabotan & 27,00 & $\mathrm{~m} 2$ & 2.250 .000 & 60.750 .000 \\
\hline 4 Gudang Bahan Baku (Jerami\& sekam), Rangka Baja Ringan & 24,00 & $\mathrm{~m} 2$ & 1.200 .000 & 28.800 .000 \\
\hline 5 Pembangunan Tempat Mesin ( No. 2, 3 \& 4), Rangka Baja Ringan & 67,50 & $\mathrm{~m} 2$ & 1.250 .000 & 84.375 .000 \\
\hline 6 Pembangunan Pembakaran, pasangan 1 Batu Bata & 16,00 & $\mathrm{~m} 2$ & 2.200 .000 & 35.200 .000 \\
\hline 7 Pembangunan Ruang Pengering (Open) Pas. 1 Batu Bata & 12,00 & $\mathrm{~m} 2$ & 2.000 .000 & 24.000 .000 \\
\hline 8 Pengadaan Mesin Pengayak, Kapasitas 480 Kg/Jam & 1,00 & Unit & 45.000 .000 & 45.000 .000 \\
\hline 9 Pengadaan Mesin Penggiling (Blender) $\emptyset 2 \mathrm{~m}$ & 1,00 & Unit & 18.000 .000 & 18.000 .000 \\
\hline 10 Pengadaan Mesin Cetak (Briket), Kapasitas $200 \mathrm{Kg} / \mathrm{jam}$ & 1,00 & Unit & 10.000 .000 & 10.000 .000 \\
\hline 11 Pembangunan Ruang Packing & 20,00 & $\mathrm{~m} 2$ & 2.000 .000 & 40.000 .000 \\
\hline 12 Pengadaan Kompeyor (Min. 3 Unit) & 3,00 & Unit & 4.500 .000 & 13.500 .000 \\
\hline 13 Pengadaan Timbangan Mobil (Uk. 4 x 4,5) & 1,00 & Unit & 50.000 .000 & 50.000 .000 \\
\hline 14 Pembangunan KM/Toilet Pekerja, 2 Unit & 6,00 & $\mathrm{~m} 2$ & 2.000 .000 & 12.000 .000 \\
\hline 15 Biaya notaris dan perijinan & & & & 10.000 .000 \\
\hline 16 Perlengkapan kantor & & & & $15.000 .000,00$ \\
\hline 17 Biaya lainnya & & & & 15.000 .000 \\
\hline total & & & & 641.625 .000 \\
\hline
\end{tabular}

Sumber : Data Primer (diolah), 2015

Dari Tabel 5 diterangkan diketahui bahwa harga lahan ukuran 20m x 20m (1 rante) di lokasi penelitian (Kecamatan Tanah Jawa, Kabupaten Simalungun) sebesar Rp. 80.000.000,-. Data ini diperoleh dari Kepala Dusun (Kadus) Marubun Jaya I, Kecamatan Tanah Jawa Kabupaten Simalungun.

Perlengkapan kantor terdiri dari komputer, printer, kertas, jaringan internet yang keseluruhan berfungi untuk menunjang kegiatan usaha briket arang. Biaya lainnya merupakan sumber biaya yang disediakan untuk memenuhi kebutuhan kebutuhan yang tidak terduga selama proses kegiatan usaha briket arang.

Ruang perngarangan, mesin pengayak, mesin pencampur, mesin pencetak briket, konveyor, oven, bangunan perkantoran, bangunan pabrik merupakan bagian inti dari kegiatan usaha briket arang.

Kendaraan operasional berupa mobol pick up (L 300), kondisi mobil bekas. Data harga didapat dari dealer mobil yang ada di kota Pematangsiantar.

Total biaya modal/investasi sebesar Rp 641.625.000,00.

\section{PaybackPeriod (PP)}

Analisa Payback Period dilakukan bertujuan untuk mengetahui jangka waktu pengembalian investasi. Hasil analisis proyek pembangunan pabrik arang briket akan 
Insandi, M.A., R.A. Kuswardani dan M.B. Sibuea . Analisis Studi Kelayakan Bisnis Pemanfaatan Limbah Agribisnis Menjadi Energi Alternatif di Kecamatan Tanah Jawa Kabupaten Simalungun.

mencapai titik balik pada saat proyek berumur satu bulan. Bila ditinjau dari umur proyek yang mencapai 5 tahun, maka pembangunan pabrik pengolahan briket arang sangat memungkinkan dan layak untuk dilaksanakan karena jangka waktu pengembalian investasi lebih kecil dari umur proyek.

\section{Net Present Value (NPV)}

Net Present Value dari usaha briket arang ini dapat dilihat pada Tabel 6 berikut ini,

Tabel 6. Net Present Value (NPV)

\begin{tabular}{|c|c|c|c|}
\hline Tahun & Net Benefit & Discount Factor & Net Benefit \\
\hline 0 & $(641.625)$ & 1 & (641.625) \\
\hline 1 & $3.336 .857,04$ & 0,89 & $2.969 .802,77$ \\
\hline 2 & $3.298 .456,96$ & 0,8 & $2.638 .765,57$ \\
\hline 3 & $3.254 .001,43$ & 0,71 & $2.310 .341,02$ \\
\hline 4 & $3.202 .794,07$ & 0,64 & $2.049 .788,21$ \\
\hline 5 & $3.144 .058,43$ & 0,57 & $1.792 .113,31$ \\
\hline & NPV & - & $11.760 .810,86$ \\
\hline
\end{tabular}

Sumber : Data Primer (diolah), 2016

Dari hasil perhitungan NPV, dapat diperoleh suatu gambaran bahwa Proyek Industri Arang Briket sangat layak, dengan nilai NPV $=11.760 .810,86$ yang berarti bahwa selama 5 tahun ke depan proyek tersebut akan menghasilkan Nilai Bersih Sekarang (NPV) sebesar Rp. 11.760.810,-.

Jika harga jual produk turun $10 \%$ dari perkiraan, perhitungan menunjukkan masih menghasilkan NPV positif.Demikian pula jika biaya produksi atau pengeluaran naik10\% juga menunjukkan nilai NPV positif.

\section{Internal Rate of Return (IRR)}

Internal Rate of Return (IRR)dari usaha briket arang dapat dilihat pada tabel berikut (000),

Tabel 7. IRR dari Usaha Briket Arang

\begin{tabular}{cclrrr}
\hline Tahun & DF 75\% & DF 120\% & Net Benefit & \multicolumn{1}{c}{$\begin{array}{l}\text { Net Benefit } \\
\text { DF75\% }\end{array}$} & \multicolumn{1}{c}{$\begin{array}{l}\text { Net Benefit } \\
\text { DF 120\% }\end{array}$} \\
\hline 0 & 1 & 1 & $(641.625)$ & $(641.625)$ & $(641.625)$ \\
1 & 0,57 & 0,45 & $3.336 .857,04$ & $1.902 .008,51$ & $1.501 .585,67$ \\
2 & 0,33 & 0,2 & $3.298 .456,96$ & $1.088 .490,80$ & $659.691,39$ \\
3 & 0,19 & 0,09 & $3.254 .001,43$ & $618.260,27$ & $292.860,13$ \\
\hline
\end{tabular}

Sumber : Data Primer (diolah), 2016

Dari perhitungan tabel 7, diperoleh suatu gambaran bahwa proyek ini sangat layak karena menghasilkan Internal Rate of Return di atas 100\% yang berarti jika tingkat suku 
bunga tersebut mencapai $100 \%$ pertahun, proyek ini masih mampu menutupi tingkat suku bunga tersebut.

\section{Sensitivitas}

Penjualan Turun Biaya Tetap

Analisis sensitivitas dengan indikator penurunan kapasitas produksi, dilakukan dengan asumsi terjadinya penurunan kapasitas olah pabrik sebesar dan 5, 10, dan 15 persen masih menghasilkan . Penurunan kapasitas olah berimplikasi pada penurunan biaya pengadaan bahan baku dan biaya bahan pembantu proses produksi. Selain itu, penurunan kapasitas olah mengakibatkan penurunan volume produksi yang berpengaruh terhadap pendapatan penjualan atau output yang dihasilkan.

Tabel 8. Net Present Value dengan penurunan kapasitas sebesar 5\%

\begin{tabular}{rrrr}
\hline Tahun & Net Benefit & Discount Factor 12\% & \multicolumn{2}{c}{$\begin{array}{c}\text { Net Benefit } \\
\text { DF 12\% }\end{array}$} \\
\hline 0 & $(594.000,00)$ & 1,00 & $(594.000,00)$ \\
1 & $3.141 .881,04$ & 0,89 & $2.796 .274,13$ \\
2 & $3.089 .224,96$ & 0,80 & $2.471 .379,97$ \\
3 & $3.030 .513,43$ & 0,71 & $2.151 .664,54$ \\
4 & $2.965 .050,07$ & 0,64 & $1.897 .632,05$ \\
5 & $2.892 .058,43$ & 0,57 & $1.648 .473,31$ \\
& NPV & - & $10.965 .423,98$ \\
\hline
\end{tabular}

Sumber : Data Primer (diolah), 2016

Tabel 9. IRR dengan penurunan kapasitas sebesar $5 \%$

\begin{tabular}{crrrrr}
\hline Tahun & DF 75\% & DF 120\% & Net Benefit & \multicolumn{1}{l}{$\begin{array}{l}\text { Net Benefit } \\
\text { DF75\% }\end{array}$} & \multicolumn{1}{l}{$\begin{array}{l}\text { Net Benefit } \\
\text { DF 120\% }\end{array}$} \\
\hline 0 & 1,00 & 1,00 & $594.000,00$ & $594.000,00$ & $594.000,00$ \\
1 & 0,57 & 0,45 & $3.141 .881,04$ & $1.790 .872,19$ & $1.413 .846,47$ \\
2 & 0,33 & 0,20 & $3.089 .224,96$ & $1.019 .444,24$ & $617.844,99$ \\
3 & 0,19 & 0,09 & $3.030 .513,43$ & $575.797,55$ & $272.746,21$ \\
\hline
\end{tabular}

Sumber : Data Primer (diolah), 2016

Tabel 10. Net Present Value dengan penurunan kapasitas sebesar $10 \%$

\begin{tabular}{clll}
\hline Tahun & Net Benefit & Discount Factor 12\% & \multicolumn{1}{c}{$\begin{array}{c}\text { Net Benefit } \\
\text { DF } 12 \%\end{array}$} \\
\hline 0 & 594.000 & 1 & 594.000 \\
1 & $2.889 .881,04$ & 0,89 & $2.571 .994,13$ \\
2 & $2.837 .224,96$ & 0,80 & $2.269 .779,97$ \\
3 & $2.778 .513,43$ & 0,71 & $1.972 .744,54$ \\
4 & $2.713 .050,07$ & 0,64 & $1.736 .352,05$ \\
5 & $2.640 .058,43$ & 0,57 & $1.504 .833,31$ \\
& NPV & - & $10.055 .703,98$ \\
\hline
\end{tabular}

Sumber : Data Primer (diolah), 2016 
Insandi, M.A., R.A. Kuswardani dan M.B. Sibuea . Analisis Studi Kelayakan Bisnis Pemanfaatan Limbah Agribisnis Menjadi Energi Alternatif di Kecamatan Tanah Jawa Kabupaten Simalungun.

Tabel 11. IRR dengan penurunan kapasitas sebesar $10 \%$

\begin{tabular}{ccrrrr}
\hline Tahun & DF 75\% & DF 120\% & Net Benefit & \multicolumn{1}{c}{$\begin{array}{c}\text { Net Benefit } \\
\text { DF75\% }\end{array}$} & \multicolumn{1}{c}{$\begin{array}{c}\text { Net Benefit } \\
\text { DF 120\% }\end{array}$} \\
\hline 0 & 1,00 & 1,00 & $594.000,00$ & $594.000,00$ & $594.000,00$ \\
1 & 0,57 & 0,45 & $2.889 .881,04$ & $1.647 .232,19$ & $1.300 .446,47$ \\
2 & 0,33 & 0,20 & $2.837 .224,96$ & $936.284,24$ & $567.444,99$ \\
3 & 0,19 & 0,09 & $2.778 .513,43$ & $527.917,55$ & $250.066,21$ \\
\hline
\end{tabular}

Sumber : Data Primer (diolah), 2016

Tabel 12. IRR dengan penurunan kapasitas 15\%

\begin{tabular}{ccrrrr}
\hline Tahun & DF 75\% & DF 120\% & Net Benefit & \multicolumn{1}{c}{$\begin{array}{c}\text { Net Benefit } \\
\text { DF75\% }\end{array}$} & \multicolumn{1}{c}{$\begin{array}{c}\text { Net Benefit } \\
\text { DF 120\% }\end{array}$} \\
\hline 0 & 1,00 & 1,00 & $594.000,00$ & $594.000,00$ & $594.000,00$ \\
1 & 0,57 & 0,45 & $2.637 .881,04$ & $1.503 .592,19$ & $1.187 .046,47$ \\
2 & 0,33 & 0,20 & $2.585 .224,96$ & $853.124,24$ & $517.044,99$ \\
3 & 0,19 & 0,09 & $2.526 .513,43$ & $480.037,55$ & $227.386,21$ \\
\hline
\end{tabular}

Sumber : Data Primer (diolah), 2016

Tabel 13. Net Present Value dengan penurunan kapasitas 15\%

\begin{tabular}{crrr}
\hline Tahun & Net Benefit & Discount Factor 12\% & \multicolumn{1}{c}{$\begin{array}{c}\text { Net Benefit } \\
\text { DF } 12 \%\end{array}$} \\
\hline 0 & & & $594.000,00$ \\
1 & $594.000,00$ & 1,00 & $2.347 .714,13$ \\
2 & $2.637 .881,04$ & 0,89 & $2.068 .179,97$ \\
3 & $2.585 .224,96$ & 0,80 & $1.793 .824,54$ \\
4 & $2.526 .513,43$ & 0,71 & $1.575 .072,05$ \\
5 & $2.461 .050,07$ & 0,64 & $1.361 .193,31$ \\
& $2.388 .058,43$ & 0,57 & $9.145 .983,98$ \\
\hline
\end{tabular}

Sumber : Data Primer (diolah), 2016

Dari hasil analisis yang dilakukan jika terjadi penurunan penjualan sebesar 5\%, 10\%, dan $15 \%$ masih menghasilkan nilai NPV positif sehingga pembangunan pabrik briket arang masih layak untuk dilaksanakan berdasarkan kriteria-kriteria investasi yang digunakan. Hal ini mengindikasikan bahwa penurunan penjualan produksi pada tingkat toleransi 5\%, 10\%, dan 15\% persen yang berkaitan dengan pasokan atau ketersediaan bahan baku masih dapat memberikan manfaat serta tidak menyebabkan aktifitas operasional pabrik briket arang tidak terganggu.

\section{SIMPULAN}

Ketersediaan bahan baku berupa sekam padi di lokasi penelitian. Proyek industri arang briket sangat layak yaitu menghasilkan NPV $=12.100 .085$ yang berarti bahwa selama 5 tahun ke depan proyek tersebut akan menghasilkan Nilai Bersih Sekarang (NPV) sebesar Rp. 12.100.085. Hasil perhitungan Internal Rate of Return di atas 100\% pertahun yang 
berarti jika tingkat suku bunga tersebut mencapai $100 \%$ pertahun, proyek ini masih mampu menutupi tingkat suku bunga tersebut. Demikian juga halnya jika harga jual lebih rendah $10 \%$ dari perkiraan atau biaya mengalami peningkatan $10 \%$ di atas perkiraan, maka proyek ini masih sangat layak. Pembangunan industri arang briket sebagai energi terbarukan sangat penting dilaksanakan sebagai upaya peningkatan pendapatan masyarakat dan sebagai upaya mendukung kelestarian lingkungan.

\section{DAFTAR PUSTAKA}

Ahmad, Subagyo. (2008). Studi Kelayakan Teori dan Aplikasi, Elex Media Komputindo, Jakarta

Anggoro, D. D., M. D. Hanif W., \& M. Z. Fathoni. (2017). Pembuatan Briket Arang dari Campuran Tempurung Kelapa dan Serbuk Gergaji Kayu Sengon. Jurnal Teknik, 38 (2), 2017, 76-80.

Johan Suwinto. (2011).Studi Kelayakan Pengembangan Bisnis. Penerbit Graha

Jumingan.( 2009).Studi Kelayakan Bisnis. Penerbit PT.Bumi Aksara: Jakarta

Jumingan. (2009).Studi Kelayakan Bisnis. Penerbit PT.Bumi Aksara: Jakarta

Kasmir, dan Jakfar, 2007, Studi Kelayakan Bisnis. Edisi kedua. Cetakan ke-4. Penerbit Kencana Prenada Media Group, Jakarta

Muhazir, Arief. (2013). Pembuatan Briket Berbahan Baku Campuran Endapan Lumpur Limbah Pabrik Kelapa Sawit Dengan Tandan Kosong Kelapa Sawit. Tugas Akhir. STIPAP Medan

Naibaho, Ponten M. (1996). Teknologi Pengolahan Kelapa Sawit, Medan : Pusat Penelitian Kelapa Sawit.

Nurhilal, M. \& R. A. Permana Tarigan. (2017). Karateristik Briket Arang Sekam Padi dan Arang Kulit Bawang Putih. Media Teknika Jurnal Teknologi Vol. 12 No. 2 Desember 2017.

Patundung, P. (2014). Pengaruh Jumlah Tepung Kanji pada Pembuatan Briket Arang Tempurung Pala. Jurnal Penelitian Teknologi Industri Vol. 6 No. 2 Desember 2014 Hal :95-102.

Prima, Astuti Handayani, Nurjanah, E., \& Rengga, W. D. (2014). Pemanfaatan Limbah Sekam Padi Menjadi Silika Gel. Jurnal Bahan Alam Terbarukan, 3(2). doi:10.15294/jbat.v3i2.3698

Putri, R. E. \& Andasuryani. (2017). Studi Mutu Briket Arang dengan Bahan Baku Limbah Biomassa. Jurnal Teknologi Pertanian Andalas Vol. 21, No. 2, September 2017.

Riseanggara, R, R. (2008). Optimasi Kadar Perekat Pada Briket Limbah Biomassa. IPB, Bogor.

Sinaga, D. (2009).Studi Kelayakan Bisnis Dalam Ekonomi Global. Penerbit Mitra Wacana Media, Jakarta

Syahputra, Andi. (2013). Pembuatan Briket Arang Berbahan Baku Campuran Tandan Kosong Kelapa Sawit Dengan Sekam Padi. Tugas Akhir. STIPAP Medan 